\title{
Key Risks in Construction Projects in Italy: Contractors' Perspective
}

\section{Ali Rostami and C.F Oduoza,}

School of Engineering, University of Wolverhampton,

WV1 1LY, UK.

\section{A.Rostami@wlv.ac.uk}

Accepted 18/06/2016

\begin{abstract}
Risk Management (RM) within small and medium-sized enterprises is gaining reconsideration from researchers to improve the weak reputation of the construction industry. However, inability to understand the benefits of the process and failure to recognise its contribution to organisational success influence the adoption and practical application of RM in SMEs. On the basis of a qualitative research with semi-structured interviews, the contributions of risk management within SMEs from three EU countries (UK, Germany and Italy) in the construction industry was discussed. 32 SMEs outlined that implementation and practice of RM improves the competitiveness of organisations in three main areas: awareness; productivity; and profitability. SMEs specified that the use of RM made valuable contribution to the efficiency of their organisations by protecting available resources. Those contributions promoted continuous improvement and supported effective use of resources that primarily enhanced the productivity and profitability of the organisations.
\end{abstract}

KEYWORDS: Risk management, construction industry, small and medium enterprises, contributions, competitiveness.

\section{INTRODUCTION}

Within organisations, a number of capabilities and managerial processes are needed to develop competitive advantages (Ulrick, 1997). Risk management is one of the key processes which enables development of organisational competitiveness under a controlled business environment (Rutkauskas, 2008). Risks in businesses influence the process of activities and 
also threaten their effectiveness. Organisations need to be able to identify these risks with a view to mitigate their impacts.

Competitive advantage factors in small-sized organisations are different from those of large firms. In smaller businesses factors such as investment, turnover, profit and employment mainly determine the competitiveness level of the organisation (Jennings and Beaver, 1997). Ulrick (1997) argued that the competitive advantage factor within an organisation is also dependent on non-financial factors such as managerial experience which enables the firm to accomplish a work better than its rivals. Clarke and Varma (1999) specified that an integrated risk management approach allows companies to consistently deliver superior performance and enhance competitiveness advantage by protecting financial and non-financial resources.

This paper examines and reviews the role of risk management on improved competitiveness in SMEs in the European construction industry, and addresses "to what extent does the risk management process impact on competitiveness in SMEs in the construction industry?"

\section{RISK MANAGEMENT FOR IMPROVED COMPETITIVENESS IN SMES}

Flanagan and Norman (1993), Akintoye and MacLeod (1997), and Chapman and Ward (2002), have depicted that the process of RM has been transformed from a simple 'add-on' process to an essential and effective practice. RM is primarily designed for technical solutions to prevent organisation from financial failure (Hammer, 1972), but also is practised to control human errors and occupational safety (Alexander, 1999).

The objective of RM either as a technical solution or a tool to prevent monetary failures is known as an improvement of business performance, which supports organisations to enhance their competitiveness. Based on a critical literature review, Clink (2001), Woods and Joyce (2003), O'Hara et al. (2005), Henschel (2007) and Altman et al. (2009) suggested that the role of RM for competitive advantage in SMEs are as follows:

- $\quad \mathrm{RM}$ in SMEs supports owner-managers to mitigate risks and unfavourable events, and aids them to prevent capital loss and think about the return on investments. Raghavan (2005) stated that the financial survival of firms heavily depends on RM capability which turns the "wait and see" policy to predict and manage process.

- RM based on strategic planning adopts operative methods to adjust time in projects (Leopoulos et al. 2006). It accelerates and facilitates the decision-making process in coping with organisation-wide changes. 
- The process of managing risk improves organisational productivity and profitability by controlling threats and opportunities which enhances business development.

- Formal and systematic process of RM enhances and streamlines internal administrative processes and enables decision-makers to remain viable in the marketplace. It benefits SMEs in developing and improving future planning and prioritisation.

- $\mathrm{RM}$ improves the efficiency of SMEs through an intellectual business management in uncertainty events. Systematic risk management processes prevent effort duplication and save external costs on insurance.

Porter (1997) stated that risk management practice optimises the organisational competitive advantage, assists top management to protect the company against catastrophic losses, and supports superior risk returns performance and shareholder value growth. Ernst and Young Global (2012) through an empirical research specified that risks within organisations need to be turned into results to improve the competitive advantage of the organisation. Turning risks into results demands effective risk management practices, which can be attained by: enhanced risk strategy; embedded risk management; optimised risk management functions; and improved controls and processes. (Clarke and Varma, 1999)

Competitive advantage in businesses is defined as the ability to perform at a better level than competitors through characteristics and resources (Christensen and Fahey 1984; Kay 1994; and Chaharbaghi and Lynch 1999). In the 1960s a framework was established to help organisations to obtain sustained competitive advantages by implementing viable strategies (Figure 1). This framework was designed to exploit the organisational internal strengths, through responding to environmental opportunities, while neutralising external threats and avoiding internal weaknesses (Ansoff, 1965; Andrews, 1971; and Hofer and Schendel, 1978 cited by Barney, 1991).

Internal Analysis

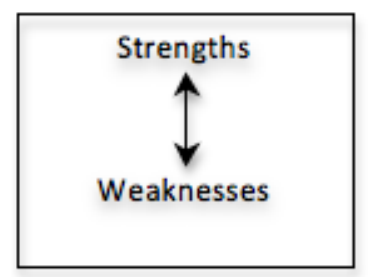

Resource based model
External Analysis

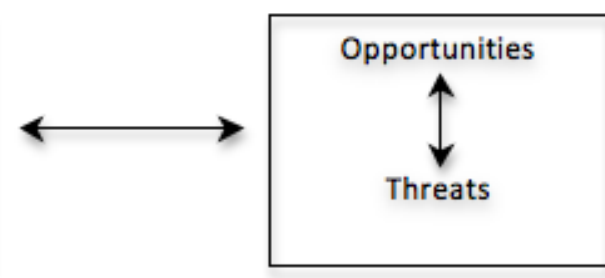

Environmental models of competitive advantage 
Figure 1: The Relationship between Traditional "Strengths, Weaknesses, Opportunities and Threats"

Porter (1998) discussed competitiveness and its connections with productivity. This theory was used to understand and evaluate the structure of an industry's business environment and was named 'Diamond' (Figure 2). The diamond model was structured on two key facts: lower cost and differentiation. In this model there were four interdependent areas; (1) strategy, structure and rivalry of organisations; (2) demand conditions; (3) industrial supporting factors; and (4) factor conditions. The diamond model illustrates precisely how each determinant is influenced by the other three determinants.

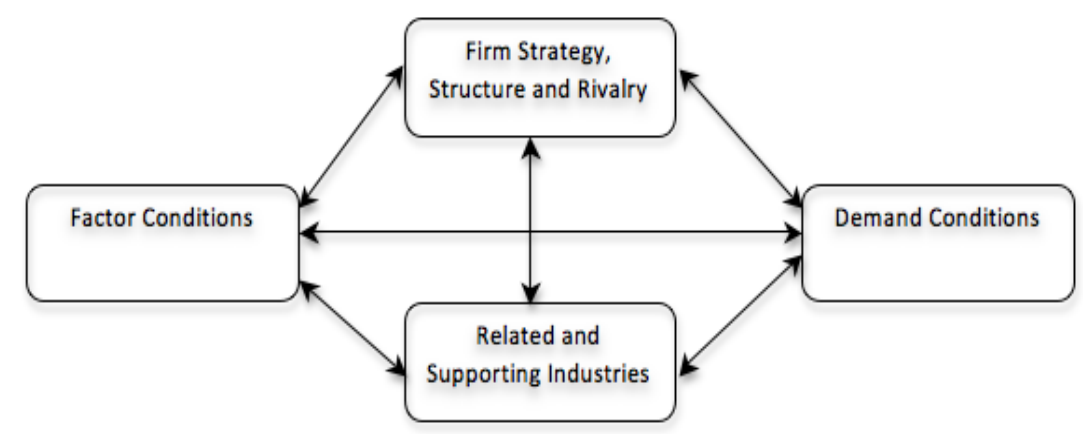

Figure 2: Porter's Diamond Model - Source: Porter (1998, p. 127)

Competitive advantages are principally measured by organisation's or nation's competencies (King et al., 2001). From the organisation's perspective, agility and ability determine the organisation's competencies. These factors assist decision-makers to respond to internal and external changes in a very timely manner. In small and medium-sized enterprises, due to their characteristics, competencies are defined by degrees of three key factors: investment efficiency, business development and organisational growth (Yan man, 2001). In this study, to assess the risk management competitiveness within SMEs in the construction industry, the organisations' perspective of competitiveness is considered.

Flanagan et al. (2005) described competitiveness in the construction sector as something that is "multi-defined, multi-measured, multi-layered, dependent, relative, dynamic and process related". Assessing the competitiveness of construction projects is a real challenge due to lack of a practical and quick method such as composite index (Flanagan et al., 2007). Researches in the construction industry indicate that firms' competitiveness equate to competitiveness in a project. Construction organisations need to run efficiently in order to accomplish their undertaken projects. Shen and Tan (2005) realised that an organisation's competitiveness can foster a project's competitiveness. Although, the method as to how an organisation's 
competitiveness could bring about competitiveness for a project has not yet been investigated (Flanagan et al., 2005).

Literature review specified that competency factors need to be considered and assessed from both organisational and project perspectives (Oz, 2001 and Flanagan et al., 2007). However, an adequately developed method that would facilitate mutual improvement of competitiveness at these different perspectives has not been established. Cattell et al. (2003) identified that organisations in any industry have to remain competitive by continuously adding value to their activities through:

- Improving operational effectiveness by use of technologies

- Mitigating inefficiencies and removing excess costs

- Increasing process effectiveness

- Enhancing business performance - productivity and profitability

An awareness of the value of risk management practices and ability to scale and take benefits of its processes improve construction organisations' competitiveness. Ernst and Young Global's (2012) research evidently confirmed that financial performances (productivity and profitability) are highly correlated with the level of integration and coordination of RM. Thus, to persuade SMEs in practise of RM there is an empirical requirement to assess to what extent the RM process impact on competitiveness in SMEs.

\section{RESEARCH METHODOLOGY}

This study was based on a qualitative research method with a comprehensive literature review and data analysis. The data for the study was obtained by means of semi-structured interviews i.e. on-line and face to face interviews. The non-probability 'self-selection' sampling technique was adopted to seek assistance from organisations who had experience in RM. In this research 32 SMEs from architecture, engineering, quantity surveyors, and construction organisations participated (Table 1). Organisations which participated in this study employed more than 10 people but less than 250 .

Saunders et al. (2009) stated that unlike quota and probability samples, there are no rules for sample size in a non-probability sampling approach; rather, the actual size depends, among other things, on available resources and the logic behind the sample selection. This argument is supported by Patton (1990), who maintains that the validity and understanding that the researcher will gain from the data in this type of sampling will have more to do with the data collection and analysis skills than the size of the sample. The sampling method used in this 
section of the study was 'purposive procedures' which a small number of projects within the construction industry were considered at the data collection stage. This provided a sample of interviewees who could grant adequate time for a detailed explanation of the key issues of the study. The study was carried out from the $10^{\text {th }}$ of October 2014 to the $15^{\text {th }}$ of February 2015.

Table 1: Organisation distribution which participated in the study

\begin{tabular}{lccccc}
\hline Organisation & Architect & Engineers & Contractors & $\begin{array}{c}\text { Quantity } \\
\text { Surveyors }\end{array}$ & Total \\
\hline Small & 3 & 5 & 5 & 4 & 17 \\
\hline Medium & 2 & 3 & 6 & 4 & 15 \\
\hline Total & 5 & 8 & 11 & 8 & 32 \\
\hline
\end{tabular}

Through the semi-structured interviews, the subject of competitiveness within SMEs was discussed. The first part of the interviews stimulated responses of participants in RM contributions in the organisations' present level of competitiveness, and the second section addressed the perceived role of RM in organisational competitiveness. Content analysis was adopted to convert the obtained large quantities of data from interviews into a meaningful and usable format. Holsti (1969) defined the content analysis as a standard methodology in social science which generates inferences based on specific characteristics of messages. Content analysis compresses large amounts of words of text into smaller numbers of categories based on a coding system (Allen and Reser, 1990). Content analysis was practised to determine the presence of certain words or concepts within sets of texts.

The first step of content analysis was the coding process. The collected data needed to be coded and broken down into categories or themes based on valid inference and interpretation. Coding and analysis of the interview sessions were accomplished by a software adoption due to the magnitude of the data that was collected. NVivo 10 was adopted for the research because of its advanced data-handling and manipulation features. The cross-interview analysis approach was used to organise the interviews. The organised data from the results of the cross-interview analysis were analysed through the content analysis approach. The autocoding by headings was applied to sort out the responses according to the relevant questions. Further, the responses were arranged through the Nodes field.

\section{RESULT AND ANALYSIS OF DATA}


The first part of the study considered the subject of competitiveness and asked SMEs to explain how the efforts and initiatives of risk management contribute to the organisation's present level of competitiveness. This question disclosed the following key factors (Table 2).

Table 2: Associated Factors in SMEs' Competitiveness in the Construction Industry

\begin{tabular}{lcccc}
\hline Competitiveness Factors & Small & Medium & Total & Percentage \\
\hline Awareness & 6 & 14 & 20 & $63 \%$ \\
\hline Efficiency & 6 & 9 & 15 & $47 \%$ \\
\hline Productivity and profitability & 4 & 7 & 11 & $34 \%$
\end{tabular}

20 out of 32 participants specified that practice of risk management enhanced their degree of awareness of business environment, which indirectly impacts the competitive advantage of the organisation. Six small-sized and fourteen medium-sized enterprises indicated that their organisational competitiveness was influenced by the awareness of decision-makers. A manager emphasised that at tendering stages, the process of managing risk through identification and assessing processes improves the degree of awareness of involved risks. The process provides a general overview of the project that helps in making decisions under forecasted circumstances (accept or reject high risk projects). Another interviewee noted; "Maximum awareness gives minimum risk". He outlined that the level of captured information within a project guaranties the success or failure of the project. This explains that the level of awareness within a project determines the competitiveness of the business. Ramlall (2003) assessed that awareness of potential risks helps supervisors to take necessary steps to reduce the impact of identified risks and enhance organisational competitiveness.

A project-manager from a medium-sized organisation highlighted the role of Community of Practice $(\mathrm{CoP})$ in organisational awareness. A CoP is a type of learning practice that is based on sharing knowledge and experience in a particular domain or area (Lave and Wenger, 1991). The interviewee claimed that the existence of a CoP comprising technical groups and feedback procedures helped to reduce risks and liabilities in construction projects. He indicated that risk management under experts' knowledge within the CoP assists to identify areas of threats and improves competitiveness of the business.

Table 2 shows that improved efficiency by the practice of risk management is the second factor that contributes to the organisational competitiveness. Fifteen organisations stated that, due to shortage of experienced personnel, they needed to find an effective way to deliver 
projects within their allocated resources. They indicated that practice of RM could assist them reduce the number of failures in their cost and time estimations. Kirytopoulos et al. (2001) through an empirical research specified that SMEs in the construction sector could develop their competitiveness by adoption of risk management, which helps to figure out the best and most efficient way to exploit resources.

The development of competitiveness in an organisation is mainly related to the links of internal processes which are founded on capabilities emerging from the entire value chain (Long and Vickers-Koch, 1995; and Thompson and Strickland, 2001). Linking the organisational internal processes helps to breakdown the functional barriers and fosters the improvement of cross-functional teams that facilitate delivery of projects and services. This practice provides opportunities for individuals to share their knowledge and skills (Pfeffer, 1994), and develops organisational reputation with more creative methods of production (Foley, 2000). A senior manager of a medium-sized company confirmed the above statement and specified that connections between processes and activities provide opportunities for employees to use their captured knowledge in RM processes to find practical solutions to problems; and that improves the efficiency of activities and consequently the reputation of the organisation.

Another interviewee stated; "we always consider risks in our projects and this process helps us to keep people satisfied with our business. RM assists our team to predict threats and opportunities, and reduce number of accidents in each project which protects the company and its integrity". The interviewee also outlined that the captured and filed data from previous projects were used in risk identification and analysis to eliminate difficulties which impact upon the efficiency of the organisation. However, another interviewee explained that it was difficult to gauge the contribution of risk management in the efficiency of the organisation because of the current business environment, "many firms are based on financial fee competition and they lower the quality of their services and cut their prices in order to attract customers".

Twenty-five out of thirty two organisations linked the organisational effectiveness to financial factors based on their relevance and impact. They mostly perceived that efficiency of business was confined to financial reporting systems calculated according to the book value and market value of the organisation. Sixteen interviewees directly commented that the efficiency of their organisations was assessed by financial criteria, and non-financial factors had less contribution. These enterprises suggested that non-financial factors such as 
knowledge and awareness involved in RM existed in their organisational effectiveness but in intangible forms which had not been considered.

Abou-Zeid (2002) stated that there are two strategies in organisational management: survival and advancement. The survival strategy was developed to attain success in the organisation's known business environment, and the advancement strategy was established to secure and guaranty future profitability (Von Krogh et al., 1994). In this study, seven organisations directly highlighted the use of survival strategy in their business that relied on the effective use of organisational assets and resources. They specified that the practise of RM in their business and projects made valuable contribution to the efficiency of the organisation by protecting the existing resources. These contributions promoted continuous improvement and supported effective use of resources that primarily enhanced productivity and profitability of the organisations.

Sahay (2005) ascertained that productivity in an organisation concerns the best value of all inputs across the entire value chain that requires a sustained improvement in management, culture and processes. Table 2 shows that eleven interviewees from four small-sized and seven medium-sized enterprises indicated that there were growth in productivity within their organisations due to the practise of RM. McLaughlin and Coffey (1990) observed that complexity of activities that impose a range of constraints on productivity need to be managed and controlled by business management processes. RM is one of those processes that decreases the complexity of activities' network and utilises productivity improvements in organisations (Mili et al., 2009). This is because of the creation of a more risk-focused culture and efficient use of resources in the organization. A manger from a medium-sized company stated "During a tender we always do not have all information or enquiries about the project. We mostly rely on RM matrix to predict probability and impact of events. Therefore, somehow we can judge as to whether we need to invest or spend money in any particular areas or not. It helps to cut some contingency costs which effectively reduces the total cost and increases productivity".

Also, increased profitability is regarded as the third factor of the risk management contribution to the organisational competitiveness. Three medium-sized enterprises named $\mathrm{RM}$ as an additional management process that helps reduce cost and time over scheduled events and boosts the quality of projects' activities. They recognised that the process influences the productivity of their organisations and consequently their profitability. 
Profitability and productivity are two organisational related factors but have distinct concepts (Strappazzon and Fisher, 2001). Profitability measures the organisational financial performance and is mainly calculated based on investments and outcomes earnings. However, productivity is a physical rather than a financial measure that can be assessed from the quantities of inputs and outputs. In this study, an owner-manager of a small firm noted that the use of RM increased productivity of his organisation but the related costs of the process i.e. technology and information gathering process decreased the net profit of the organisation.

\section{PERCEIVED ROLE OF RISK MANAGEMENT IN ORGANISATIONAL COMPETITIVENESS IN SMES}

The participants in this study were asked to specify how implementation and practise of RM could contribute to their organisational competitiveness. Table 3 shows the perceived factors that impact the SMEs' organisational competitiveness in the EU construction industry.

Table 3: Perceived Factors in SMEs' Competitiveness in the EU Construction Industry

\begin{tabular}{lcccc}
\hline Competitiveness Factors & Small & Medium & Total & Percentage \\
\hline Enhanced efficiency & 12 & 14 & 26 & $81 \%$ \\
\hline Increased profitability & 11 & 10 & 21 & $66 \%$ \\
\hline Enhanced productivity & 9 & 8 & 17 & $53 \%$ \\
\hline
\end{tabular}

In this study, enhancement in organisational efficiency through the practise of RM was noted by twenty-six enterprises. They indicated that continuous improvement in performance through systematic risk management could prevent extra costs of uncertainties and save internal resources. It was highlighted that the process provides a clear understanding of the probability and impact of activities' risks, which further facilitates allocation of organisational resources for managing risks in a more efficient way. The process also provides an opportunity for practitioners to identify the strengths and weaknesses of their businesses and improve quality as a competitive advantage. Nineteen of the organisations stated that risk management implementation would also enable them to analyse uncertainties, which would help them to understand to what extent they need to protect their business objectives and to what extent they could protect them (according to their available resources). 
Eleven small-sized and ten medium-sized enterprises noted that structured training programmes for RM would help in risk management implementation, and perceived that it would further increase profitability of their SMEs in the construction industry. The participants outlined that in order for the risk management to be effective, risks in activities need to be considered as dynamic factors. Majority of the participants highlighted that maintaining information about the identified risks up-to-date is a real challenge in their risk management practices. In an effective risk management, the involved risks need to be continuously monitored and controlled to avoid duplication of effort, and save organisational resources. The interviewees also indicated that RM needed to be integrated with time and cost management processes to present individual and combined impacts of each risk on the project's activities. This process provides a more accurate perspective of projects that supports management to make decisions based on the most beneficial situations. The ability to manage risks and persistently make decisions according to the degrees of threats, will lead to organisational competitiveness.

In this study, enhanced productivity was perceived as the third factor of risk management implementation. Seventeen interviewees noted the following as prerequisites for establishing a productive RM process:

- Having connections with objectives of the organisation: a structured RM process should clearly include business objectives. There needs to be an obvious understanding of risks that could influence business missions and visions.

- Conform to organisational capability: scope of the processes in RM needs to be compatible with organisational resources. Each activity in the process of managing risks requires a certain amount of resources such as equipment, knowledge and capital, which needs to be determined based on the organisation's existing resources.

- Support by key individuals: collaboration of people within an organisation has to be in place in order to execute a structured risk management. This development needs to be led by an expert under the supervision of top-management. RM cannot be implemented as an individual assessment. Existing information and data from different parts of the firm need to be gathered in one place.

- Tools and techniques selection: many factors are involved in the use of risk management's tools and techniques. Firms need to have an established infrastructure to deploy a specific set of techniques. 
The data analysis of this study indicated that RM has a significant impact on the SMEs' competitiveness in the construction industry.

\section{LIMITATIONS OF THE STUDY AND FUTURE RESEARCH}

The findings of this study cannot be generalised statistically for the whole of the EU as it was constrained geographically, with respondents drawn only from a self-selection sample of construction enterprises in the UK, Germany and Italy. The findings represent a snapshot of impacts and contributions of risk management on organisations from the perspective of SMEs. Another important limitation is that this study focused on domestic SMEs and did not take into account the international construction enterprises. The third limitation is the relatively small sample size. A larger sample could produce different results by addressing multiple class sections. Further studies should focus on a specific category (i.e. size of organisation, private or public sectors) and employ a larger number of cases representing the population of interest, in order to obtain more detailed information. However, the results of the study specified the benefits of risk management to SMEs' competitiveness which were consistent with the outcomes of previous studies.

\section{CONCLUSION}

This study examined the contributions of risk management to SMEs' competitiveness in the EU construction industry. Implementation and practice of RM improves competitiveness of SMEs in three main areas: awareness; productivity; and profitability. The process of managing risk through identification and assessing processes improves the degree of SMEs' awareness of involved risks. It provides a general overview of the project that helps to make decisions based on the most beneficial situations. In construction industry, level of awareness within a project determines the competitiveness of the business. RM practices also deliver opportunities for individuals to share their knowledge and skills, and develop organisational reputation with more creative methods of production. SMEs specified that the use of RM made valuable contribution to the efficiency of the organisation by protecting the existing resources. These contributions promoted continuous improvement and supported effective use of resources that primarily enhanced productivity and profitability of the organisations. RM implementation also enables SMEs to analyse uncertainties, which would help them to understand to what extent they need to protect their business objectives.

\section{REFERENCES}


Abou-Zeid E. (2002), A knowledge management reference model, Journal of Knowledge Management, Vol. 6, No. 5, pp. 486-499.

Akintoye A. S. and MacLeod M. J. (1997), Risk analysis and management in construction, International Journal of Project Management, Vol. 15, No. 1, pp. 31-38.

Allen B. and Reser D. (1990), Content analysis in library and information science research, Library and Information Science Research, Vol. 12, No. 3, pp. 251-260.

Altman E., Sabato G. and Wilson N. (2009), The Value of Qualitative Information in SME Risk Management, CMRC, Leeds University Business School, UK.

Andrews K. R. (1971), The concept of corporate strategy: Homewood, IL: Dow Jones Irwin. Ansoff H. I. (1965), Corporate strategy, New York: McGraw-Hill.

Barney J. (1991), Firm resources and sustained competitive advantage, Journal of Management, Vol. 17, No. 1, pp. 99-120.

Cattell K., Flanagan and Jewell C. (2003), Competitiveness and productivity in the construction industry: the importance of definitions, Conference hosted by the construction industry development board, South Africa, pp. 25-35.

Chaharbaghi K. and Lynch R. (1999), Sustainable competitive advantage: towards a dynamic resource-based strategy, Management Decision, vol. 37, no. 1, pp. 45-50.

Chapman C. and Ward S. (2002), Managing Project Risk and Uncertainty, A Construction Simple Approach to Decision Making, John Wiley \& Sons, Ltd.

Christensen K. and Fahey L. (1984), Building distinctive competences into competitive advantage, Strategic Planning Management, February, pp. 113-23.

Clarke C. J. and Varma S. (1999), Strategic Risk Management: the New Competitive Edge, Long Range Planning, Vol. 32, No. 4, pp. 414-424.

Clink S. (2001), Risk management in small business, PhD thesis, Glasgow Caledonian University, p. 52.

Ernst and Young Global (2012), Turing risk into results: How leading companies use risk management to fuel better performance, Accessed on 9th December 2014, http://www.ey.com/Publication/vwLUAssets/Turning_risk_into_results/\$FILE/Turning\%20ri sk\%20into\%20results_AU1082_1\%20Feb\%202012.pdf 
Flanagan R. and Norman G. (1993), Risk Management and Construction, Oxford: Blackwell Scientific Publications.

Flanagan R., Jewell C., Ericsson S. and Henricsson J.P.E. (2005), Measuring Construction Competitiveness in Selected Countries, Final Report, School of Construction Management and Engineering, the University of Reading.

Flanagan R., Weisheng L., Liyin S., and Jewell C. (2007), Competitiveness in construction: a critical review of research, Construction Management and Economics, Vol. 25, No. 9, pp. 989-1000.

Foley G. (2000), Facing reality - the role of HR in developing high performance organisations, Training and Development in Australia, Vol. 27, No. 4, pp. 20-23.

Hammer R. W. (1972), Handbook of System and Product Safety, Englewood Cliffs, N. J.: Prentice-Hall, Inc.

Henschel T. (2007), Risk Management Practices in the Main Industries of German Small to Medium-Sized Enterprises, An Empirical Investigation, $\mathrm{PhD}$ thesis, Napier University, Edinburgh, UK.

Hofer C. and Schendel D. (1978), Strategy formulation: Analytical concepts, St. Paul, MV: West.

Holsti O. R., (1969), Content Analysis for the Social Sciences and Humanities, Reading: Mass.

Jennings P. and Beaver G. (1997), The performance and competitive advantage of small firms: A management perspective, International Small Business Journal, Vol. 15, No. 2, pp. 63-75.

Kay J. (1994), Foundations of Corporate Success, Oxford University Press, Oxford.

King A. W., Fowler S. W. and Zeithaml C. P. (2001), Managing organisational competencies for competitive advantage: The middle-management edge, Academy of Management Executive, Vol. 19, No. 2, pp. 95-106.

Kirytopoulos K., Leopoulos V. and Malandrakis C. (2001), Risk Management: A powerful tool for improving efficiency of project oriented SMEs, SMESME International Conference, Denmark, pp. 331-339. 
Lave J. and Wenger E. (1991), Situated Learning: Legitimate Peripheral Participation. Cambridge: Cambridge University Press.

Leopoulos V. N., Kirytopoulos K. A. and Malandrakis C. (2006), Risk Management for SMEs: Tools to use and how, Production Planning \& Control, Vol. 17, No. 3, pp. 322-332.

Long C. and Vickers-Koch M. (1995), Organisational dynamics, in Thompson, A and Strickland, A., Readings in Strategic Management, Irwin McGraw Hill, Boston, MA.

McLaughlin C. P. and Coffey S. (1990), Measuring productivity in services, International Journal of Service Industry Management, Vol. 1, No. 1, pp. 46-64.

Mili A., Bassetto S., Siadat A. and Tollenaere M. (2009), Dynamic risk management unveil productivity improvements, Journal of Loss Prevention in the Process Industries, Vol. 22, No. 1 , pp. $25-34$.

Oz O. (2001), Sources of competitive advantage of Turkish construction companies in international markets, Construction Management and Economics, Vol. 19, No. 2, pp. 135-44.

O'Hara R., Dickety, N. and Weyman, A. (2005), Good Practice in Assessing Workplace Risks by Small and Medium-sized Enterprises, Risk Management. An International Journal, Vol. 7, No. 1, pp. 31-41.

Patton M. Q. (1990), Qualitative evaluation and research methods, Newbury Park, CA: Sage. Pfeffer J. (1994), Producing sustainable competitive advantage through effective management of people, Harvard business school press, Boston.

Porter I. (1997), Big or Small, All Can Win With Risk Management, Australian Financial Review, June 17.

Porter M. E. (1985). Competitive Advantage. Free Press. ISBN 0-684-84146-0.

Raghavan R. S. (2005), Risk Management in SMEs, The Institute of Chartered Accountant, October, pp. 528-535.

Ramlall S. (2003), Managing Employee Retention as a Strategy for Increasing Organizational Competitiveness, Applied H.R.M. Research, Vol. 8, No. 2, pp. 63-72.

Rutkauskas A. V. (2008), On the sustainability of regional competitiveness development considering risk, Technological and Economic, Baltic Journal on Sustainability, Vol. 14, No. 1, pp. 89-99. 
Sahay B.S. (2005), Multi-factor productivity measurement model for service organisation, International Journal of Productivity and Performance Management, Vol. 54, No. 1, pp. 7-22.

Saunders M., Lewis P. and Thornhill A., (2009), Research Methods for Business Students, 5th Edition, London Pitman

Shen L. Y. and Tan Y. T. (2005), Applying the fuzzy resources allocation (Fra) model by different contractors for different types of projects, The Chinese Research Institute of Construction Management, pp. 212-23.

Strappazzon L. and Fisher W. (2001), What is the difference between productivity and profit?, Department of Natural Resources and Environment Victoria, Australia, November 2001.

Thompson A. and Strickland A. (2001), Crafting and executing strategy, McGraw Hill, New York, NY.

Ulrick D. (1997), Organising around capabilities, In Hesselbein, F. Goldsmith, M., Beckhard, R. (Eds), The organisation of the future, Jossey-Bass, New York, NY.

Von Krogh G., Roos J. and Slocum K. (1994), An essay on corporate epistemology, Strategic Management Journal, Vol. 15, Issue S2, pp. 53-71.

Woods A. and Joyce P. (2003), Owner-Managers and the Practice of Strategic Management, International Small Business Journal, Vol. 21, No. 2, pp. 181-195.

Yan man W. T. (2001), Entrepreneurial competencies and the performance of small and medium enterprises in the Hong Kong service sector, PhD thesis, The Hong Kong Polytechnic University, Hong Kong. 